\title{
Vocabulary Attrition among Adult English as A Foreign Language Persian Learners
}

\author{
Azadeh Asgari (Corresponding author) \\ C-3-22, Selatan Perdana, Taman Serdang perdana, Seri Kembangan \\ Serdang, PO box 43300, Selangor, Malaysia \\ Tel: 60-17-350-7194Ｅ-mail: Azia.Asgari@gmail.com
}

\section{Ghazali Bin Mustapha}

Department of Language and Humanities, Faculty of Educational Studies

Universiti Putra Malaysia, Serdang, Malaysia

Tel: 60-19-650-8340Ｅ-mail: gm@upm.edu.educ.my

\begin{abstract}
This study aims to investigate the attrition rate of EFL concrete and abstract vocabulary among continuing and non-continuing Iranian female and male English language learners across different proficiency levels. They are students of a University and majored in different fields (between 20 and 25 years old). There was no treatment in this study where the researcher compared two groups on the same variables. Hence, the design of the current study is an ex-post facto design.

A 40-item vocabulary test which varied across two proficiency levels are used to measure rate of vocabulary attrition as the instrument of this research. In the two stages, after an interval of three months, the students are taken the same tests. The results revealed that there was no significant difference between EFL attrition rate of abstract and concrete nouns among the continuing students across different proficiency levels. However, this hypothesis was rejected for the non-continuing learners at intermediate and advanced proficiency level.

Keywords: Vocabulary attrition, Abstract and concrete nouns, Continuing and non-continuing students, Proficiency level Introduction
\end{abstract}

The study of language attrition has recently emerged as a new field of study. The conception of loss in language skills occurred in a conference at the University of Pennsylvania (UPenn) in 1980. This conference was dedicated to the theoretical basis of research in the field of language attrition and other related conferences that probed the process of language loss as a natural disorder from many other perspectives.

Kopke (2004) stated that "attrition refers to the natural (non-pathological) loss of a language in bilinguals; generally speaking, changes in the linguistic environment and termination of an instructional program may lead to attrition"(p.15).

In terms of language learning, researchers have used the same definition to develop a framework which involved divergent methods of data collection, sampling and instrumentation on language attrition in papers and publications. This taxonomical framework was the one provided by Van Els (1986, as cited in Kopke and Schimd, 2004) which was as following categories:

1. L1 loss in L1 environment: Dialect loss

2. L1 loss in L2 environment: Immigrant

3. L2 loss in L1 environment: Foreign language attrition

4. L2 loss in L2 environment: Language reversion in elderly people

The main phases reported in the field of language attrition are the above categories as the framework has divided the field of attrition into four simple and discrete categories. But, in order to gain a better and clearer picture of the concept of attrition, other methodological issues such as the distinction between attrition in adults and children, the effect of age at the amount of attrition, the effect of age at bilingualism, the effect of gender at the amount of L2 attrition and so forth also needs to be taken into consideration.

\section{Stages in Language Attrition}

Weltens and Grendel (1993) suggested that in "the first stage of language attrition that it takes longer to retrieve the required information, and the next stage, may be the required information becomes inaccessible"(p.135). In this stage, under some conditions, attriters can retrieve the required information but in other conditions they cannot. 
Weltens and Grendel claimed that a good example in this regard is the fact that one may be very capable of recognizing certain words but cannot produce them actively. And, finally, if the periods of disuse continue, information might become completely and permanently inaccessible. Hence, language recovery should be viewed as a reactivation process. In this regard, Hansen (2001a) stated that the first sign of language attrition is not the loss of certain items but rather an increase in the length of time which is needed for their retrieval.

According to Smith (2002, as cited in Kopke, 2007), stages of language attrition are classified into three stages. Smith remarks that the first stage of attrition can be characterized by the deviation in performance of attriters, while their competence remains intact. In the second stage, the attriter is in the possession of a new extremely conditioned variety of his/her language.

\section{Cognitive Processes \& Causes of Attrition}

Probably one of the most widely studied themes in the language attrition process is whether the attrition phenomenon of language skills occurs in the reverse order of acquisition and attrition to verify how second language develops. Smith (2002, as cited in Kopke and Schmid, 2004) pointed out "that language attrition is not the consequence of lack of L1 use alone; but first language is generally replaced by another language and this language is often assumed to influence the process of L1 attrition"(p.135). Smith (2002, as cited in Kopke and Schmid, 2004) hypothesized that "transfer is one of the most important processes which determine attrition"(p.156). This hypothesis called cross-linguistic interference has been adopted by many researchers and supported by many studies.

Pavlenko (2002, as cited in Kopke and Schmid, 2004) remarked that the transfer from L2 undeniably plays a role in L1 attrition; on the contrary, Kopke (1999, as cited in Kopke and Schmid, 2004) pointed out that transfer is not the only source of linguistic change in L1 attrition. However, Paradis (1985, as cited in Tomiyama, 2000b) remarked that "language transfer is a fundamental process in loss" (p.29).

With regard to the cause of attrition, Yamgur (2004) stated that

"Depending on the approach to attrition within which researchers work, different theories and hypotheses concerning language loss have been postulated. Taking contact linguistic, sociolinguistic, language change or acquisition perspectives bring about varying hypotheses about the causes of language loss. Due to this inconsistency there are no commonly agreed definitions of language attrition, loss, or shift as yet" (p.135).

Based on the previous attrition studies, some hypotheses have supported the account of how and when transfer occurs. The first hypothesis of transfer is proposed by Kerlinger (1986, as cited in Tomiyama, $2000 \mathrm{~b}$ ) as that the degree of markedness determines the occurrence of transfer. The second hypothesis is put forward by Waas (1996, as cited in Tomiyama, 2000b) "only if L1 and L2 have structures meeting a crucial similarity measure will there be interference" (p.131). Consequently, in the context of L1 attrition, the similarity of L1 and L2 is a necessary condition for transfer to occur.

\section{Important Variables in Attrition Studies}

At the first specialized conference of language loss, Gardener and Macintyre (1993) stated that affective factors influence the amount of language retention and language attrition. In 1999, Nagasawa found that those participants whose motivation decreased over the school year used Japanese little outside the class. Those who are motivated will seek more opportunities to use the language during the period of disuse; that is why they can retain much more linguistic information (Hansen \& Shewell, in press).

Oxford (1982) proposed that studies in the field of EFL/ESL attrition would inform language teachers regarding the long-term effect of their teaching methodology. Results of research reported that there is a high and positive correlation between personality factors, such as attitude, motivation and language maintenance. Likewise, she indicated that summer recess does not have a detrimental effect on language maintenance and individuals lose different aspects of second language throughout non-use intervals. Hence, there is no one rule preferable to all language attriters.

In Canada, Gardner, Lalonde and Macpherson (1985, as cited in Hansen and Shewell, in press) carried out a study which displayed a high degree of correlation was displayed between less favorable attitude and lower language use with attrition of speaking and understanding skill as reported on a can-do scale but not with attrition of reading. Gardner et al. (1985) suggested that "the attitudinal motivational factors may exert their greatest influence on attrition primarily during the acquisition period by influencing the level of competence acquired" (p.531).

In another study which was conducted by Ebbinghaun (1885), it was indicated that in spite of the proficiency level of students being the best and clear predictor of attrition, attitude and motivation of students have indirectly influenced on attrition throughout their study. Ebbinghaun (1885, as cited in Weltens and Grendel, 1993) elaborated that there is a positive correlation between proficiency level and amount of attrition; in other words the" more you know the more you will forget". 
Kuhberg (1992, as cited in Kopke and Schmid, 2004) stated that educational level of subject, is also another factor playing an important role in L2 attrition studies. Educational level can also be the cause of absence of attrition in some studies. (Ammerlaan (1996), Bouba et al. (2002), Gurel (2004) as cited Kopke and Schmid, 2004) cited that another factor which affects L2 attrition in foreign language environments is length of stay abroad. Empirical evidence indicated that after a short period of stay in an L2 environment, reversal of language dominance occurs and is manifested by faster picture naming in second language than L1.

Hutz (2004) remarked that "L1 attrition studies have not reached conclusive evidence about the effect of time on L1 attrition"(p.193). Montrul (2002, as cited in Kopke and Schmid, 2004) pointed out that this degree of erosion may be to the extent that psycho and neurolinguistic methods can detect no trace of it. Before reaching critical period, it is easier for a child to learn an L2; at the same time, it is more likely that the child forgets her L1. In accordance with the results of several studies such as (Nicolladis and Grabois (2002), Pallier et. al (2003) as cited in Kopke and Schmid, 2004) suggested that before reaching the critical period, L1 can be easily replaced.

Reetz-Kurashige (1999) maintained that such factors such as personal characteristics of returnees, age, length of time abroad, length of time back, the proficiency level at study onset and high competence at the onset of the study were the most predictive variables for amount of L2 retention. Additionally, being older groups did not guarantee high retention; whereas it is in contrast to Olshtain's study that older retained more, in this study. Reetz-Kurashige claimed that "it is not one factor but a combination of factors that predict strong maintenances, near-native speaking English ability was practically a requirement for minimal attrition" (p.41).

\section{Learning and Relearning Vocabulary}

In 1986, Cohen declared that "each exposure to a word has the potential of increasing learner's depth of knowledge about that word"(p.146). Cohen claimed that some words come into learners' vocabulary very easily without much attention whereas some others need conscious effort involving either rote repetition or organizational techniques.

Each vocabulary - spoken and written form- has certain characteristics including conceptual and indicating meaning in the context in which it can be used and the syntactic restrictions that language imposes on the word. Cohen (1986) noted that the most obvious type of forgetting vocabulary involves forgetting the conceptual or denotative meaning of a word or its spoken or written form. Furthermore, he believed that there are many aspects of a word that should be learned because many aspects of a word also might undergo attrition.

In 2000, De Bot and Stoessel conducted a study on the difference between learning and relearning of vocabulary. In this research the German participants relearned those L2 Dutch words that subjects claimed they forgot results of this study displayed that subjects who knew words before showed development. Hansen (2001) stated that the words that are to be learned for the first time in L1/L2 cannot reach the required activation level as fast as forgotten words reach through relearning.

\section{Method \& Materials}

The present research compares two or more groups of the subject of study on the same variables that have done in past researches. As there is no treatment in this study, the design selected for this study is the quantitative research (ex-post facto). The designation of ex-post facto, from Latin for "after the fact", is used to determine the natural course of events. The method of ex-post facto research is investigated the cause-and-effect relationships between the independent and dependent variables.

The objectives of the present study are to measure the level of attrition of the abstract and concrete vocabulary among continuing and non-continuing students' performances at two proficiency levels in both stages. The independent variables in this study are the between-group and within-group variables. The between-group variables include status in two levels: continuing vs. non-continuing students and level of proficiency in two levels: intermediate and advanced. The within-group variables include: stages with two levels: stage 1 and stage 2 (the comparison which is to show whether or not attrition has taken place) and vocabulary items with two levels: concrete vs. abstract. The dependent variables which include students' scores in the vocabulary test are categorized across modalities and contexts.

This study is conducted in the Tehran capital of the Islamic Republic of Iran, at the KISH English language institute. The subjects in this study consist of two hundred male and female adult Iranian language learners who have registered in IPL3 \& APL (intermediate and advanced) levels at the KISH English language institute in mixed classes during the spring and summer seasons in 2008.

An accidental sampling of the main major of non-probability sampling involves using available cases for a study is employed in this research. Hence, the sampling procedure is the EFL learners from different classrooms or to have volunteers to take the tests in one session at both stages. 
For both levels, the summer term has thirty sessions during the period of three months. The respondents attended English classes thrice a week. Table.1. displays the distribution of the subjects obviously.

The 40-item vocabulary test is carried out to recognize which and how many lexical items have significant effects of attrition on the students. This test is prepared for those in the intermediate and advanced levels. In addition, the same vocabulary tests are administrated among continuing and non-continuing groups across different proficiency levels at two stages.

This test was administered twice with a three month interval. The instrument was chosen standardized achievement tests for reading and writing; on the other hand, the validity of the test has been checked thoroughly by the English language teachers who have some years of teaching experience at KISH English language institute. The reliability test was applied to measure the inter-item consistency. The reliability of this test also was 0.769 in the first stage and 0.767 in the second phase.

The data of this study were collected in two separate stages with an interval period of three months. In the first stage which was towards the end of the spring term (the end of June 2008), all of the participants sat for the vocabulary test. After the period of three months, which was the second stage, the continuing group (those who would be attending classes in the next term, the end of September 2008) took the same vocabulary tests in the class. In order to find out the amount of attrition, the performance of the participants in the second stage is compared with their earlier performance in the first stage. Likewise, the present study has its own limitations and is constrained by a number of delimitations which are as follows:

At first, the types and numbers of vocabulary which is examined in this research are limited to abstract and concrete nouns at the intermediate and advanced proficiency levels. Second, the number of respondents involved in this study is only two hundred students where 100 respondents participated in the intermediate level and 100 respondents participated in advanced level among continuing and non-continuing adult students. Next, the attrition of learning strategies and teaching methodology, the degree of motivation, attitude, affective and other individual factors are not controlled in this study. Likewise, for non-continuing students, it was not possible to control for extraneous variables such as references to dictionaries or other forms of assistance.

The data collected was coded and entered into the Statistical Package for the Social Science [SPSS version 16 for Windows Vista], a statistics computer program which was used to process and analyze the data. In the current study, both types of statistics, the descriptive (such as the frequency distribution, percentages, means, and standard deviations) and inferential (one-way ANOVA), were conducted. For this study, a five percent $(\alpha=0.05)$ level is determined as the accepted level of significance for statistical analysis.

\section{Results}

These demographic variables help to describe the profiles of the involved respondents and it could be observed that majority of the respondents in both stages (56.5 percent) were males. In this study there were two proficiency levels which were 50 percent for the whole population. The subjects of the present research were divided in two groups at two different stages with three months interval. The rate of continuing students who participated in this research was 57.5 percent while non-continuing students were 42.5 percent.

Fortunately, all of the respondents were Iranian students with ages ranging from 20 to 25 years old who born and lived in Iran/Tehran with Persian as their mother language. The majority of them were university students from different fields with most of their occupations are simply being students (86.6\%).

The 40-item vocabulary test consisted of two types of nouns. For each level, 20 concrete nouns and 20 abstract nouns were randomly extracted from vocabulary books or texts which learners were used in their classes. The vocabulary tests were prepared for those in the intermediate and advanced levels among continuing and non-continuing groups; furthermore the same vocabulary tests are employed at the both stages.

Referring to above Table, there is no missing value at the stages in this research. The mean for abstract and concrete nouns are 18.15 and 18.21 for continuing group while for non-continuing student, the mean for abstract and concrete nouns are 18.29 and 18.34 , respectively.

\section{Level of Attrition of the Abstract \& Concrete Nouns}

The first research question is to examine the following null hypothesis: there are no differences between EFL attrition rate of the abstract and concrete nouns among the continuing and non continuing students at the intermediate level. And second research question is evaluated the same variables at the advanced proficiency level. The level of significance is $\alpha=0.05$. 
With referring to table, the mean of the concrete nouns can be seen to improve at the advanced level in the second stage. Analysis of variance (ANOVA) is conducted to gather information regarding respondents with the abstract and concrete nouns for continuing student at the intermediate and advanced levels.

The results presented in the above table indicated that neither of the stages nor the proficiency levels have shown any significant effects. That is to say, students who continue their exposure of the English language did not experience significant attrition with the abstract nouns $(\mathrm{F}=2.809, \mathrm{p}>.05)(\mathrm{F}=.586, \mathrm{p}>.05)$.

The results indicate again that attrition of the concrete nouns do not occur on the continuing students at the intermediate level $(\mathrm{F}=.026, \mathrm{p}>.05)$ and at the advanced level $(\mathrm{F}=1.890, \mathrm{p}>.05)$.

To conclude, there are no differences between EFL attrition rate of concrete and abstract nouns among continuing students across different proficiency levels. Further, a similar descriptive statistics and analysis is conducted on the abstract and concrete vocabulary. The following tables of analysis display attrition which has taken place on the non-continuing group in different stages.

As shown in Table, the mean of the abstract and concrete nouns are diminished for the non-continuing group in the second stage. One-way ANOVA is conducted to find out the significant differences between proficiency levels and stages of the abstract nouns.

The results in the Table 4.9., displays that there is a significance of 0.041 in the stage for the non-continuing students. As mentioned earlier, the significant level of the whole analysis process is $\alpha=0.05$; therefore attrition of the abstract nouns takes place on the non-continuing students at the intermediate level $(\mathrm{F}=4.310, \mathrm{p}<.05)$.

As shown in the table 4.10., the results of the analyzed factors revealed that there was significant of the abstract nouns on the non-continuing students at advanced level $(\mathrm{F}=4.578, \mathrm{p}<.05)$.

The analysis of variance procedure is used to find out the concrete nouns for non-continuing students across different proficiency levels. The results of the ANOVA conducted are as presented in the following tables.

In referring the Table 4.11., indicate that there are significant effects on the concrete nouns at intermediate levels for the non-continuing students $(\mathrm{F}=5.759, \mathrm{p}<.05)$.

Based on the results in the Table 4.12., there are significant effects on the concrete nouns at advanced proficiency levels for the non-continuing students, as well. The significant level across different proficiency levels are lower than $0.05(\mathrm{~F}=4.100, \mathrm{p}<.05)$. This shows that, in the second stage of the concrete nouns, there is a reduction in the students' performance and their performance lead to the reduction of the significance level. In other words, EFL attrition takes place on the concrete nouns for the non-continuing group at both proficiency levels. Consequently, the results demonstrate that there are differences between attrition of the abstract and concrete nouns in non-continuing students at the intermediate and advanced level.

\section{Conclusions \& Implication}

The findings of this research indicated that the continuing students do not undergo significant attrition of the abstract and concrete nouns, whereas non-continuing students undergo a significant attrition of the abstract and concrete nouns across different proficiency level. The absence of attrition on continuing students is not against the researcher's expectation. While, the results of this study are in contrast with what De Groot and Keijzer (2000, as cited in Ross, 2002) have proved that attrition of abstract nouns does not take place faster than the concrete nouns. In addition, the results elaborated that the continuing students did not experience attrition with the abstract and concrete nouns. This might be due to the short period of disuse. In spite of the short period of non-use, non-continuing students have shown a trend of attrition of the abstract and concrete nouns at two different proficiency levels. The amount of attrition might turn out to be significant in a long run and displayed a trend of attrition of abstract nouns at the stages. In contrast to past studies, abstract nouns turned out to be more resistant to attrition.

In previous studies such as from Bahrick (1984) and Olshtain (1989), it was shown that the advanced students were more resistant to attrition in comparison to the low-proficiency students. But in this study, the advanced students experienced attrition, as well. This might be due to some intervening variables such as the amount of out-of-class exposure, attitude, motivation, teaching methodology and so forth which are not involved in this study.

Baharik's study (1984) indicated that the first 5 years of second language disuse regardless of the proficiency levels, all attriters will experience the same attrition. In 1885, Ebbingham noted that the more one knows the more one will tend to forget; so, there is a positive correlation between proficiency level of attriters and the amount of attrition. This study also supported the findings of other studies that learners who are in the advanced level experience a high attrition than of those with low-proficiency. Tomiyama (1999) asserted that the first and second language attrition 
set in within six months of disuse. In this research, the 3 months interval of nouns of the language could lead to attrition also.

According to Cohen (1986), vocabulary which is added most recently is found to be the most vulnerable area which leads to attrition. This study also supported the types of vocabulary which lead to attrition across different proficiency levels on the continuing and non-continuing groups. Nouns are known to be easier to learn than verbs or adverbs, but according to the regression hypothesis, they can be forgotten sooner.

The findings of this study shed some light of the attrition of vocabulary of concrete and abstract nouns across different proficiency levels among continuing and non-continuing students. In past studies, the effects of class exposure on attrition have not been investigated, hence this study shed some light on the role of class in EFL vocabulary attrition. Additionally, this research shows that attrition is not limited on the non-continuing students as even the continuing students have the possibility to experience attrition, as well.

English language teachers are required to identify differences between the abstract and concrete nouns in the English text books and to draw students' attention more on them as well as to provide the students with more practices on vocabulary. English language teachers should make modifications with their teaching methodologies based on the results of this study as in to put more emphasis on the areas which turn out to be vulnerable to attrition.

\section{References}

Ammerlaan, R. (1996). "You get a bit wobbly..." Exploring bilingual lexical retrieval processes in the context of first language attrition. Unpublished Doctoral Dissertation, Nijmegen: Katholieke University Nijmegen.

Bahrick, H. (1984). Fifty years of second language attrition: Implications for programmatic research. The Modern Language Journal, 68, pp.105- 118.

Cohen, A. (1986). Forgetting foreign language vocabulary. In B.Weltens, K.de Bot \& T. Van Els (Eds.), Language Attrition in Progress. Dordrecht, the Netehrlands: Foris, pp.143-158.

De Bot, K. \& Stoessel, S. (2000). In search of yesterday's words: Reactivating a long forgotten language. Applied Linguistics, 21/3, pp.333-353.

Ebbinghaun, H. (1885). Über das gedächtnis. Untersuchungen zur experimentellen psychologie. Leipzig: Duncker \& Humblot.

Gardner, R. C., Lalonde, R. N., Moorcroft, R. \& Evers, F. T. (1987). Second language attrition: The role of motivation and use. Journal of Language and Social Psychology, 6(1), pp.29-47.

Gardner, R. C., \& Macintyre, P.D.(1993). One the measurement of affective variables in second language learning. Language learning, 43, pp.157-194.

Hansen, L. (2001a). Language attrition: The fate of the start. Annual Review of Applied Linguistics, 21, pp. 60-73.

Hansen, L. (2002). Saving in the relearning of second language vocabulary: The effect of time and proficiency. Language Learning, 52, 4, pp. 653-678.

Hansen, L., \& Shewell, J. (In Press). Keeping a Second Language: The influence of literacy and motivation in the attrition of Japanese, Chinese and Korean. Unpublished manuscript, Brigham Young University.

Hutz, M. (2004). Is there a natural process of decay? A longitudinal study of language attrition. In M. Schmid et al. (Eds.), First Language Attrition (pp.189-206). USA: John Benjamins North America.

Kopke, B. (1999). L'attrition de la premiere langue chez le bilingue tardif: implications pour l'etude psycholinguistique de biliguisme. Unpublished Ph.D. diss, Universite de Toulouse-LeMirail.

Kopke, B. (2004). Neurolinguistics aspects of attrition. Journal of Neurolinguistics, Vol. 17, pp.3-30.

Kopke, B. (2007). Language attrition at the crossroads of brain, mind, and society. In B. Köpke/M. Schmid/M. Keijzer/Susan Dostert (ed.): Language Attrition. Theoretical perspectives, 9-37, Amsterdam: John Benjamins.

Kopke, B. \& Schmid, M. (2004). Language attrition: The next phase. In Monika S. Schmid, B. Kopke, M.Keijzer and L.Weilemar(Eds.), First language attrition: Interdisciplinary perspectives on methodological issues (pp.1-47). Amsterdam: John Benjamins.

Kuhberg, H. (1992). Longitudinal L2-attrition versus L2-acquisition in three Turkish children-Empirical findings. Second Language Research 8(2), pp.138-154.

Montrul, S. (2002). Incomplete acquisition and attrition of Spanish tense/ aspect distinctions in adult bilinguals. Bilingualism: Language and Cognition 5, pp.39-68. 
Nagasawa, S. (1999). Learning and losing Japanese as a second language: A multiple case study of American university students. In L. Hansen (Ed.), Second language attrition in Japanese contexts (pp.169-199). New York: Oxford University Press.

Oxford, R. (1982). Research on language loss: A review with implications for foreign language teaching. The Modern Language Journal, 66, pp.106-169.

Pavlenko, A. (2002). Poststructuralist Approaches to the Study of Social Factors in L2.In V. Cook (Ed.), Portraits of the L2 User (pp.277-302). Clevedon: Multilingual Matters.

Reetz-Kurashige, A. (1999). Japanese returnee's retention of English-speaking skills: Change in verb usage over time. In L. Hansen (Ed.) Second language attrition in Japanese contexts (pp.21-58). New York: Oxford University Press.

Schmid, M. S. (2004). First Language Attrition: The Methodology Revised, International Journal of Bilingualism, 8, pp.239-255.

Smith, L. R. (2002). The social architecture of communicative competence: A methodology for social-network research in sociolinguistics. International Journal of the Sociology of Language, 153, pp.133-160.

Tomiyama, M. (2000b). Cross-Linguistics influence in L2 attrition. JACET Bulletin, Vol. 32, pp.123-136.

Van, Els, T. (1986). An overview of European research on language attrition. In B.Weltens, K. de Bot and T. van Els (Eds.), Language Attrition in Progress (pp.318).Dordrecht: Foris.

Waas, M. (1996). Language Attrition Down under. Frankfurt: Peter Lang.

Weltens, B., \& Grendel, M. (1993). Attrition of vocabulary knowledge. In R. Schreuder \& B. Weltens (Eds.), The Bilingual Lexicon. (pp.135-156). Amsterdam: John Benjamin.

Yamgur, K. (2004). Issues in finding the appropriate methodology in language attrition research. In M. Schmid et al. (Eds.), First language attrition (pp.133-164). USA: John Benjamin North America.

Table 1. Distribution of Respondents

\begin{tabular}{|l|c|c|c|c|}
\hline \multirow{2}{*}{ Proficiency } & \multicolumn{2}{c|}{ Continuing students } & \multicolumn{2}{c|}{ Non-Continuing students } \\
\cline { 2 - 5 } & Female & Male & Female & Male \\
\hline Intermediate & 23 & 29 & 22 & 26 \\
\hline Advanced & 25 & 38 & 17 & 20 \\
\hline N & 48 & 67 & 39 & 46 \\
\hline TOTAL & \multicolumn{2}{|c|}{$\mathbf{1 1 5}$} & \multicolumn{2}{|c|}{} \\
\hline
\end{tabular}

Table 2. Distribution of variables at both levels of the test on both groups

\begin{tabular}{|l|c|c|c|c|}
\hline \multirow{2}{*}{ Valid } & \multicolumn{2}{|c|}{ Continuing } & \multicolumn{2}{c|}{ Non-Continuing } \\
\cline { 2 - 5 } & Abstract & Concrete & Abstract & Concrete \\
\hline Missing & 230 & 230 & 170 & 170 \\
\hline Mean & 0 & 0 & 0 & 0 \\
\hline Median & 18.15 & 18.21 & 18.29 & 18.34 \\
\hline S.D & 18 & 18 & 19 & 19 \\
\hline Variance & 1.259 & 1.193 & 1.357 & 1.296 \\
\hline Minimum & 1.585 & 1.424 & 1.842 & 1.680 \\
\hline Maximum & 14 & 15 & 12 & 14 \\
\hline
\end{tabular}


Table 3. Descriptive statistics of the Continuing students' performance with the Abstract and Concrete nouns at two levels for both stages

\begin{tabular}{|c|c|c|c|c|c|}
\hline \multicolumn{2}{|c|}{ Proficiency Level } & \multicolumn{2}{|c|}{ Abstract } & \multicolumn{2}{|c|}{ Concrete } \\
\hline & & \multirow{2}{*}{$\begin{array}{c}\text { Stage 1 } \\
17.88 \\
\end{array}$} & \multirow{2}{*}{$\begin{array}{c}\text { Stage2 } \\
18.29 \\
\end{array}$} & \multirow{2}{*}{$\begin{array}{c}\text { Stage1 } \\
18.10 \\
\end{array}$} & \multirow{2}{*}{$\begin{array}{r}\text { Stage2 } \\
18.06 \\
\end{array}$} \\
\hline Intermediate & Mean & & & & \\
\hline & $\mathrm{N}$ & 52 & 52 & 52 & 52 \\
\hline & Std. Deviation & 1.182 & 1.273 & 1.176 & 1.259 \\
\hline & Std. Error of Mean & .164 & .177 & .163 & .175 \\
\hline \multirow[t]{4}{*}{ Advanced } & Mean & 18.29 & 18.11 & 18.17 & 18.46 \\
\hline & $\mathrm{N}$ & 63 & 63 & 63 & 63 \\
\hline & Std. Deviation & 1.250 & 1.309 & 1.225 & 1.105 \\
\hline & Std. Error of Mean & .157 & .165 & .154 & .139 \\
\hline
\end{tabular}

Table 4. The ANOVA results on the effects of attrition of the Abstract nouns on the Continuing students at Intermediate level

\begin{tabular}{|c|c|c|c|c|c|}
\hline Source & Sum of Squares & df & Mean Square & $\mathbf{F}$ & Sig. \\
\hline Stage & & & & & \\
\hline Between Groups & 4.240 & 1 & 4.240 & 2.809 & .097 \\
\hline Within Groups & 153.981 & 102 & 1.510 & & \\
\hline
\end{tabular}

Table 5. The ANOVA results on the effects of attrition of the Abstract nouns on the Continuing students at Advanced level

\begin{tabular}{|c|c|c|c|c|c|}
\hline Source & Sum of Squares & df & Mean Square & $\mathbf{F}$ & Sig. \\
\hline Between Groups & .960 & 1 & .960 & .586 & .445 \\
\hline Within Groups & 203.079 & $\begin{array}{c}12 \\
4\end{array}$ & 1.638 & & \\
\hline
\end{tabular}

Table 6. The ANOVA results on the effects of attrition of the Concrete nouns on the Continuing students at Intermediate level

\begin{tabular}{|c|c|c|c|c|c|}
\hline Source & Sum of Squares & df & Mean Square & $\mathbf{F}$ & Sig. \\
\hline Between Groups & .038 & 1 & .038 & .026 & .872 \\
\hline Within Groups & 151.346 & 102 & 1.484 & & \\
\hline
\end{tabular}

Table 7. The ANOVA results on the effects of attrition of the Concrete nouns on the Continuing students at Advanced level

\begin{tabular}{|c|c|c|c|c|c|}
\hline Source & Sum of Squares & df & Mean Square & $\mathbf{F}$ & Sig. \\
\hline Between Groups & 2.571 & 1 & 2.571 & 1.890 & .172 \\
\hline Within Groups & 168.730 & 124 & 1.361 & & \\
\hline
\end{tabular}


Table 8. Descriptive statistics of the Non-Continuing students' performance with the Abstract and Concrete nouns in both Stages

\begin{tabular}{|c|c|c|c|c|c|}
\hline \multirow{2}{*}{\multicolumn{2}{|c|}{ Proficiency Level }} & \multicolumn{2}{|c|}{ Abstract } & \multicolumn{2}{|c|}{ Concrete } \\
\hline & & \multirow{2}{*}{$\begin{array}{r}\text { Stage 1 } \\
18.52 \\
\end{array}$} & \multirow{2}{*}{$\begin{array}{c}\text { Stage2 } \\
18.00 \\
\end{array}$} & \multirow{2}{*}{$\begin{array}{c}\text { Stage 1 } \\
18.42 \\
\end{array}$} & \multirow{2}{*}{$\begin{array}{c}\text { Stage2 } \\
17.81 \\
\end{array}$} \\
\hline Intermediate & Mean & & & & \\
\hline & $\mathrm{N}$ & 48 & 48 & 48 & 48 \\
\hline & Std. Deviation & 1.167 & 1.288 & 1.108 & 1.347 \\
\hline & Std. Error of Mean & .168 & .186 & .160 & .194 \\
\hline \multirow[t]{4}{*}{ Advanced } & Mean & 18.65 & 18.03 & 18.92 & 18.32 \\
\hline & $\mathrm{N}$ & 37 & 37 & 37 & 37 \\
\hline & Std. Deviation & 1.585 & 1.343 & 1.064 & 1.435 \\
\hline & Std. Error of Mean & .261 & .221 & .175 & .236 \\
\hline
\end{tabular}

Table 9. The ANOVA results on the effects of attrition of the Abstract nouns on the Non-Continuing students at Intermediate level

\begin{tabular}{|r|c|c|c|c|c|}
\hline \multicolumn{1}{|c|}{ Source } & Sum of Squares & df & Mean Square & F & Sig. \\
\hline Stage & & & & & \\
\hline Between Groups & 6.510 & 1 & 6.510 & 4.310 & .041 \\
\hline Within Groups & 141.979 & 94 & 1.510 & & \\
\hline
\end{tabular}

Table 10. The ANOVA results on the effects of attrition of the Abstract nouns on the Non-Continuing students at Advanced level

\begin{tabular}{|c|c|c|c|c|c|}
\hline Source & Sum of Squares & df & Mean Square & $\mathbf{F}$ & Sig. \\
\hline Stage & & & & & \\
\hline Between Groups & 11.365 & 1 & 11.365 & 4.578 & .036 \\
\hline Within Groups & 178.757 & 72 & 2.483 & & \\
\hline
\end{tabular}

Table 11. The ANOVA results on the effects of attrition of the Concrete nouns on the Non-continuing students at Intermediate level

\begin{tabular}{|c|c|c|c|c|c|}
\hline Source & Sum of Squares & df & Mean Square & $\mathbf{F}$ & Sig. \\
\hline Stage & & & & & \\
\hline Between Groups & 8.760 & 1 & 8.760 & 5.759 & .018 \\
\hline Within Groups & 142.979 & 94 & 1.521 & & \\
\hline
\end{tabular}

Table 12. The ANOVA results on the effects of attrition of the Concrete nouns on the Non-continuing students at Advanced level

\begin{tabular}{|c|c|c|c|c|c|}
\hline Source & Sum of Squares & df & Mean Square & $\mathbf{F}$ & Sig. \\
\hline Stage & & & & & \\
\hline Between Groups & 6.541 & 1 & 6.541 & 4.100 & .047 \\
\hline Within Groups & 114.865 & 72 & 1.595 & & \\
\hline
\end{tabular}

